\title{
Stratospheric Ozone Intercomparison Campaign (STOIC) 1989: Overview
}

\author{
J. J. Margitan, ${ }^{1}$ R. A. Barnes, ${ }^{2,3}$ G. B. Brothers, ${ }^{2,3}$ J. Butler, ${ }^{4}$ J. Burris, ${ }^{5}$ B. J. \\ Connor, ${ }^{6}$ R. A. Ferrare, ${ }^{7.8}$ J. B. Kerr, ${ }^{9}$ W. D. Komhyr, ${ }^{10,11}$ M. P. McCormick, ${ }^{6}$ \\ I. S. McDermid, ${ }^{1}$ C. T. McElroy, ${ }^{9}$ T. J. McGee, ${ }^{5}$ A. J. Miller, 12 M. Owens, ${ }^{13}$ \\ A. D. Parrish, ${ }^{14}$ C. L. Parsons, ${ }^{15}$ A. L. Torres, ${ }^{15}$ J. J. Tsou, ${ }^{16}$ T. D. Walsh, ${ }^{1}$ \\ and D. Whiteman ${ }^{17}$
}

\begin{abstract}
The NASA Upper Atmosphere Research Program organized a Stratospheric Ozone Intercomparison Campaign (STOIC) held in July-August 1989 at the Table Mountain Facility (TMF) of the Jet Propulsion Laboratory (JPL). The primary instruments participating in this campaign were several that had been developed by NASA for the Network for the Detection of Stratospheric Change: the JPL ozone lidar at TMF, the Goddard Space Flight Center trailer-mounted ozone lidar which was moved to TMF for this comparison, and the Millitech/LaRC microwave radiometer. To assess the performance of these new instruments, a validation/intercomparison campaign was undertaken using established techniques: balloon ozonesondes launched by personnel from the Wallops Flight Facility and from NOAA Geophysical Monitoring for Climate Change (GMCC) (now Climate Monitoring and Diagnostics Laboratory), a NOAA GMCC Dobson spectrophotometer, and a Brewer spectrometer from the Atmospheric Environment Service of Canada, both being used for column as well as Umkehr profile retrievals. All of these instruments were located at TMF and measurements were made as close together in time as possible to minimize atmospheric variability as a factor in the comparisons. Daytime rocket measurements of ozone were made by Wallops Flight Facility personnel using ROCOZ-A instruments launched from San Nicholas Island. The entire campaign was conducted as a blind intercomparison, with the investigators not seeing each others data until all data had been submitted to a referee and archived at the end of the 2-week period (July 20 to August 2, 1989).

Satellite data were also obtained from the Stratospheric Aerosol and Gas Experiment (SAGE II) aboard the Earth Radiation Budget Satellite and the total ozone mapping spectrometer (TOMS) aboard Nimbus 7. An examination of the data has found excellent agreement among the techniques, especially in the $20-$ to $40-\mathrm{km}$ range. As expected, there was little atmospheric variability during the intercomparison, allowing for detailed statistical comparisons at a high level of precision. This overview paper will summarize the campaign and provide a "road map" to subsequent papers in this issue by the individual instrument teams which will present more detailed analysis of the data and conclusions.
\end{abstract}

\footnotetext{
'Jet Propulsion Laboratory, California Institute of Technology, Pasadena.

${ }^{2}$ Chemal, Incorporated, Wallops Island, Virginia.

${ }^{3}$ Now at ManTech, Wallops Island, Virginia.

${ }_{5}^{4}$ Hughes STX Corporation, Lanham, Maryland.

${ }^{5}$ Laboratory for Atmospheres, NASA GSFC, Greenbelt, Maryland.

${ }^{6}$ Atmospheric Sciences Division, NASA LaRC, Hampton, Virginia.

${ }^{7}$ Universities Space Research Association, NASA GSFC, Greenbelt, Maryland.

${ }^{8}$ Now at Hughes STX Corporation, Lanham, Maryland.

${ }^{9}$ Atmospheric Environment Service, Downsview, Ontario, Canada.

${ }^{10}$ NOAA Climate Monitoring and Diagnostics Laboratory (formerly Geophysical Monitoring for Climate Change), Boulder, Colorado.

"Now at CIRES, University of Colorado, Boulder.

${ }^{12}$ NOAA Climate Analysis Center, Washington, D. C.

${ }^{13}$ Department of Physics, University of Maryland, College Park.

${ }^{14}$ Department of Physics and Astronomy, University of Massachusetts, Amherst.
}

Copyright 1995 by the American Geophysical Union.

Paper number 95JD00509.

0148-0227/95/95JD-00509\$05.00

\section{Introduction}

Measurement of the abundance of ozone in the Earth's stratosphere and its susceptibility to modification due to a variety of natural and anthropogenic causes has been a central focus of atmospheric research for decades. As theonly significant atmospheric absorber of near-UV solar radiation, ozone abundance not only controls the flux of solar UV at ground level but also plays a major role in creating the temperature structure of the stratosphere. In the past two decades we have seen a dramatic improvement in our knowledge of the processes controlling stratospheric ozone, now recognizing that the simple production of ozone from solar photodissociation of molecular oxygen is bal-

\footnotetext{
${ }^{15}$ Wallops Flight Facility, NASA GSFC, Wallops Island, Virginia.

${ }^{16}$ Lockheed Engineering and Sciences Company, Hampton, Virginia.

${ }^{17}$ Laboratory for Terrestrial Physics, NASA GSFC, Greenbelt. Maryland.
} 
Table 1. Stratospheric Ozone Intercomparison Campaign

\begin{tabular}{|c|c|c|c|c|c|}
\hline Investigator & Institution & Instrument & $\begin{array}{c}\text { Altitude, } \\
\text { km }\end{array}$ & Location & \begin{tabular}{l}
\multicolumn{1}{c}{ PDT } \\
Observation \\
Time, hours
\end{tabular} \\
\hline I. S. McDermid & JPL & lidar (JL) & $20-50$ & TMF & $22-24$ \\
\hline T. McGee & GSFC & lidar (GL) & $20-45$ & TMF & $00-05$ \\
\hline A. Parrish/B. Connor & Millitech/LaRC & microwave (MM) & $20-64$ & TMF & $22-05$ \\
\hline \multirow{2}{*}{ C. Parsons/R. Barnes } & WFF & $\mathrm{ROCOZ}(\mathrm{RO})$ & $20-60$ & SN & $12-15$ \\
\hline & & ECC sondes (WS, MS) & $0-35$ & $\begin{array}{l}\text { TMF/Mu } \\
\text { TMF }\end{array}$ & $\begin{array}{l}23-01 \\
07-19\end{array}$ \\
\hline \multirow[t]{2}{*}{ W. D. Komhyr } & NOAA & $\begin{array}{l}\text { Dobson } \\
\text { Umkehr/Dobson }\end{array}$ & $\begin{array}{l}\text { column } \\
0-50\end{array}$ & TMF & SR, SS \\
\hline & & ECC sondes (NS) & $0-40$ & TMF & $23-02$ \\
\hline \multirow{2}{*}{ J. Kerr/T. McElroy } & AES/Canada & Brewer & column & TMF & $07-19$ \\
\hline & & Umkehr/Brewer & $0-50$ & TMF & SR, SS \\
\hline M. P. McCormick & Langley & SAGE II (SA) & $10-60$ & Sat & SR \\
\hline A. J. Krueger & GSFC & TOMS & column & Sat & noon \\
\hline A. J. Miller & NOAA & meteorological data & & Sat & \\
\hline
\end{tabular}

PDT, Pacific daylight time. JPL, Jet Propulsion Laboratory; GSFC, Goddard Space Flight Center; WFF, Wallops Flight Facility; NOAA, National Oceanic and Atmospheric Administration; AES, Atmospheric Environment Service. Two-letter codes in parentheses in column 3 are used to identify data in the figures. TMF, Table Mountain Facility; SN, San Nicholas Island; Mu, Point Mugu; Sat, satellite measurement; SR, sunrise; SS, sunset.

anced by a series of catalytic destruction processes involving the odd hydrogen, nitrogen, and chlorine families. While these species exist as a consequence of natural sources of precursor trace gases in the lower atmosphere, we now recognize that mankind has the capability to significantly increase source gas emissions and, consequently, change in significant ways the ozone destruction processes. Concerns in the past decades have centered on emissions from supersonic transports, space shuttle and rockets, degradation of fertilizer, increased biological activity/productivity, and perhaps best known emissions of chlorine and bromine compounds (chlorofluorocarbons, halons, and other halocarbons). The localized, seasonal Antarctic ozone hole provides highly visible evidence of the susceptibility of ozone to destruction; the much smaller global decrease inferred from longer-term data sets demonstrates the pervasive extent of ozone decline [World Meteorological Organization (WMO), 1985, 1988, 1991].

The existence of ozone over a wide range of concentrations and atmospheric altitudes and pressures has led to the development of a wide variety of techniques for measuring it by utilizing rocket, balloon, ground, and satellite platforms on a variety of spatial and temporal integration scales. Although space-borne techniques are clearly the only way of obtaining global ozone measurements, the desire to identify very small (few percent) changes in ozone over long timescales (decades) requires that the satellite sensors not be used in isolation; rather, ongoing campaigns of ground truth and intercomparison are needed, not only to provide an assessment of the strengths and weaknesses of the various techniques but also to provide a means of comparing data sets obtained by different instruments at different times.

Toward this end, a number of intercomparison campaigns have been conducted for ozone-measuring instruments (see WMO [1985] for a summary), including the Ozone Intercomparison Campaign in 1981, the Balloon Ozone Intercomparison Campaign (BOIC) in 1983-1984 [Hilsenrath et al., 1986], and the Balloon Intercomparison Campaign (BIC) in 1982-1983. A particularly gratifying result of these campaigns was that it does indeed appear that it is possible to make ozone measurements in the stratosphere within an accuracy of a few percent over an altitude range from 15 to $40 \mathrm{~km}$.

In the past few years a number of new instruments have been developed specifically for the role of identifying longterm trends in stratospheric compostion. In addition to their role in the international Network for the Detection of Stratospheric Change (NDSC), these instruments would also provide a crucial validation/long-term calibration standard for satellite sensors such as the solar backscatter ultraviolet (SBUV/2) aboard the NOAA weather satellites and the various instruments aboard the Upper Atmosphere Research Satellite (UARS) (CLAES, MLS, HALOE, ISAMS). Although these new instruments promise significantly improved capability over many of the older techniques, the existence of the long-term database from those older instruments makes it mandatory that a detailed intercomparison campaign be carried out to assess the relative performance and to provide a means to interrelate the various data sets.

To carry out this comparison, the Stratospheric Ozone Intercomparison Campaign (STOIC) was conducted for a 2-week period in July-August 1989 at the Jet Propulsion Laboratory Table Mountain Facility (TMF) near Pasadena, California. The participating instruments are shown in Table 1 , along with their observing location and observing times. The timing of the campaign was chosen to minimize atmospheric variability as a factor and to allow for the maximum opportunity for observations and satellite coincidences. To further minimize atmospheric variability, the instruments were, to the extent practical, colocated at TMF, and observations were made as close together in time as possible. Subsequent analysis of the results (see below) demonstrates that this objective was achieved. For this campaign, the altitude region of interest was $20-50 \mathrm{~km}$, although some instruments have performance capabilities beyond that range.

A very significant aspect of this intercomparison was the adherence to a data protocol to ensure that the various instrument results were "blind." For the entire 2-week period no investigator saw the results of any other investi- 
gator, and each day's results were turned in to an independent coordinator. Investigators followed their standard data analysis procedures. Investigators were free throughout the period to revise their initial blind results based on performance information obtained from their own instrument as the campaign progressed, leading to a final set of blind data for comparison. After the end of the 2-week comparison period these blind results were studied. As will be discussed later, they are in excellent agreement. Nonetheless, they do highlight some specific instrument problems and discrepancies, sometimes as simple as data analysis software errors. On the basis of blind comparisons, some teams did reanalyze their data to generate "revised" data sets. These revisions, fully discussed in this sequence of papers, led to a second set of revised comparisons. The conclusion from the STOIC series is that the newly developed instruments of the NDSC have the capability to perform measurements at accuracies approaching $5 \%$ over the critical 20 -to $40-\mathrm{km}$ altitude range, with uncertainties increasing to greater than $10 \%$ by $50 \mathrm{~km}$.

\section{Instruments}

The participating instruments listed in Table 1 are briefly described in the following subsections: The main site for the campaign was TMF at an altitude of $7500 \mathrm{ft}(2300 \mathrm{~m})$ in the San Gabriel Mountains north of Los Angeles $\left(34.4^{\circ} \mathrm{N}\right.$, $117.7^{\circ} \mathrm{W}$ ). The JPL lidar had been operating at TMF for some time prior to this campaign. The Goddard Space Flight Center (GSFC) trailer-mounted lidar had previously been at TMF and returned for STOIC. Both are excimer laser-based systems. The $110-\mathrm{GHz}$ microwave instrument was newly installed at TMF. These three instruments were the newly developed ones for the NDSC. The microwave radiometer has the capability of making both day and night measurements of ozone. The lidars could only be operated at night and had to be operated sequentially to avoid interference.

For comparison with these instruments, rocket ozonesondes (ROCOZ-A) were launched by personnel from the

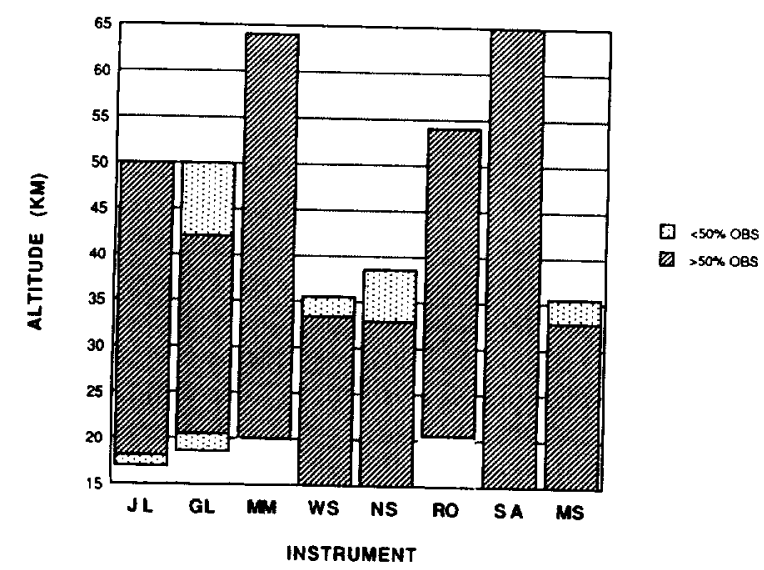

Figure 1. Altitude ranges for the STOIC instruments, showing where data were reported on more than $50 \%$ of the observations and less than $50 \%$ of the observations. Note, for example, that SAGE shows full coverage, although there were only three SAGE observations in this period: all of them had data over the whole range. On the other hand, GL had 12 observations, but not all of them covered their whole altitude range.
Table 2. STOIC Observations

\begin{tabular}{|c|c|c|c|c|c|c|c|c|}
\hline Date & $\mathrm{JL}$ & GL & MM & WS & NS & RO & SA & MS \\
\hline 890720 & $x$ & $x$ & $x$ & $x$ & & $X$ & & $\mathrm{X}$ \\
\hline 890721 & $\mathrm{X}$ & $\mathrm{X}$ & $\mathrm{X}$ & $x$ & $x$ & & & $X$ \\
\hline 890722 & $X$ & & $\mathrm{X}$ & $\mathrm{x}$ & & & & $\mathrm{X}$ \\
\hline 890723 & $\mathrm{X}$ & $\mathrm{X}$ & $X$ & $\mathrm{X}$ & $x$ & & $X$ & \\
\hline 890724 & $x$ & $x$ & $X$ & $x$ & $x$ & $x$ & $X$ & $x$ \\
\hline 890725 & $X$ & $\mathrm{X}$ & $X$ & $\mathrm{X}$ & $\mathrm{x}$ & & $X$ & $x$ \\
\hline 890726 & $\mathrm{X}$ & $x$ & $\mathrm{X}$ & $x$ & $\mathrm{X}$ & $X$ & & $X$ \\
\hline 890727 & $X$ & $x$ & $X$ & $x$ & $X$ & $x$ & & $\mathrm{X}$ \\
\hline 890728 & $X$ & & $\mathrm{X}$ & & & $x$ & & $\mathrm{x}$ \\
\hline 890729 & $\mathrm{x}$ & $X$ & $\mathrm{X}$ & $\mathrm{X}$ & & & & $X$ \\
\hline 890730 & $\mathrm{X}$ & $\mathrm{X}$ & $X$ & $\mathrm{x}$ & $x$ & & & $X$ \\
\hline 890731 & $X$ & $X$ & $X$ & $\mathrm{X}$ & $\mathrm{X}$ & & & $\mathrm{X}$ \\
\hline 890801 & $\mathrm{X}$ & $x$ & $\mathrm{x}$ & $X$ & $x$ & & & $\mathrm{X}$ \\
\hline 890802 & $\mathrm{X}$ & $\mathrm{x}$ & $\mathrm{X}$ & $\mathrm{X}$ & $\mathrm{X}$ & $x$ & & $\mathrm{X}$ \\
\hline Observation & 14 & 12 & 14 & 13 & 10 & 6 & 3 & 13 \\
\hline
\end{tabular}

Read 890720 as July $20,1989$.

Wallops Flight Facility (WFF) at the U.S. Navy site on San Nicholas Island, approximately 100 miles west of TMF. Balloon ozonesondes (electrochemical concentration cell (ECC)) were launched by WFF personnel at both Point Mugu (supporting San Nicholas) and TMF, using their standard procedures. Personnel from the NOAA Climate Monitoring and Diagnostics Laboratory (CMDL), formerly Geophysical Monitoring for Climate Change (GMCC), also launched ECC sondes from TMF using their own, slightly different, procedures. Both groups launched at night when the lidar observations were made. The NOAA group also operated a Dobson instrument at TMF for both column and profile data (the latter using the Umkehr technique). Additionally, a Brewer spectrometer from Atmospheric Environment Service (AES)/Canada was operated at TMF, also performing column and (Umkehr) profile measurements. Satellite observations were made by the Stratospheric Aerosol and Gas Experiment (SAGE) II instrument on ERBS on a number of overpasses, and column data were obtained from the (TOMS) instrument aboard Nimbus 7. Meteorological data were provided by NOAA Climate Analysis Center (CAC). The in situ UV photometers that performed so well in BOIC could not be flown for this campaign due to the lack of suitable landing areas in the heavily populated southern California region. A ground-based Dasibi was also used for measuring surface ozone abundance which, although not directly relevant to the STOIC measurements, is of value in understanding diurnal and day-to-day changes in the column amount. The surface measurements are not discussed further here but are presented by McDermid and Walsh [this issue].

The operating altitude ranges and dates of operation for the instruments are shown in Figure 1 and Table 2. Table 3 contains precision and accuracy information for the individual instruments at a variety of altitudes. These performance claims are those of the individual investigators, and no attempt to critically evaluate them by the STOIC team was made. The individual instrument papers should be consulted for the basis of the figures.

\section{Brief Descriptions of the STOIC Instruments GSFC Stratospheric Ozone Lidar}

The GSFC lidar is a mobile system mounted in a 45 -footlong trailer. The instrument transmitted two laser wave- 
Table 3. Precision, Accuracy, and Range Resolution

\begin{tabular}{|c|c|c|c|c|c|c|c|c|c|}
\hline & Altitude & $\mathrm{JL}$ & GL & MM & WS & NS & RO & $\mathrm{SA}$ & Umkehr \\
\hline $\mathbf{P}$ & 50 & $5-25$ & $10-15$ & 5 & & & 5 & 5 & \\
\hline A & 50 & $10-50$ & $20-30$ & 9 & & & 7 & 8 & \\
\hline $\mathbf{R}$ & 50 & 8 & at $45 \mathrm{~km}$ & 14 & & & 4 & 5 & \\
\hline $\mathbf{P}$ & 40 & $2-5$ & 5 & 5 & & 10 & 3.5 & 5 & 5 \\
\hline A & 40 & $4-10$ & 10 & 8 & & 20 & 7 & 8 & 12 \\
\hline $\mathbf{R}$ & 40 & 4 & 5 & 10 & & 0.5 & 4 & 1 & 12 \\
\hline $\mathbf{P}$ & 30 & 1 & 1 & 4 & 6 & 3 & 3.5 & 5 & 5 \\
\hline A & 30 & 2 & 2 & 6 & 10 & 5 & 7 & 8 & 12 \\
\hline $\mathbf{R}$ & 30 & 1 & 2.5 & 8 & 0.3 & 0.5 & 4 & 1 & 14 \\
\hline $\mathbf{P}$ & 20 & 1 & 1 & 4 & 6 & 3 & 5 & 5 & 8 \\
\hline A & 20 & 2 & 2 & 7 & 10 & 5 & 7 & 8 & 12 \\
\hline $\mathbf{R}$ & 20 & 1 & 1 & 10 & 0.3 & 0.5 & 4 & 1 & 13 \\
\hline
\end{tabular}

P. precision (\%); A, accuracy (\%); R, range resolution $(\mathrm{km})$. The individual instrument papers should be consulted for the origin and exact meaning of these parameters. They may not be strictly comparable among the very different techniques in use here.

lengths: $307.9 \mathrm{~nm}$ generated by a line-narrowed $\mathrm{XeCl}$ laser, and $355 \mathrm{~nm}$, the third harmonic of a Nd:YAG laser. Backscattered light, at the transmitted wavelengths, was collected using a 30-inch telescope, separated by dichroic optics, and detected by photomultiplier tubes in a photoncounting mode. Two detectors were used for each transmitted wavelength to increase the dynamic range of the lidar. Differential absorption provides the basis for the extraction of an ozone profile from the backscattered returns. Ozone absorbs at 307.9 and is much less absorbent at $355 \mathrm{~nm}$ (about 3 orders of magnitude less). Therefore an analysis of the difference in slope between returns at the two wavelengths results in a vertical profile of ozone. Because of the small difference in absorption at high altitudes where the concentration is small, it is necessary to integrate the returns for approximately 4 hours to achieve the necessary signal to noise. This amounts to $10^{6}$ shots at $307.9 \mathrm{~nm}$ and $2.5 \times 10^{5}$ at $355 \mathrm{~nm}$. Temperature is also extracted from the $355-\mathrm{nm}$ return. Because of interference from Mie scattering, the temperature profile is limited to a lower altitude of $30 \mathrm{~km}$. During STOIC, temperatures were retrieved to an altitude above $70 \mathrm{~km}$ [Ferrare et al., this issue]. The GSFC lidar has been discussed in detail in a previous publication [McGee et al., 19911 .

\section{JPL Stratospheric Ozone Differential Absorption Lidar}

Complete details of the JPL-TMF differential absorption lidar system and the data analysis procedures have been published elsewhere [McDermid and Godin, 1989; McDermid et al., 1990a, b]. Briefly, a high-power (100 W), narrowbandwidth, tunable, xenon chloride ( $\mathrm{XeCl}$ ) excimer laser system provides directly the absorbed probe wavelength at $307.9 \mathrm{~nm}$. The reference wavelength, $353.2 \mathrm{~nm}$, is generated by stimulated Raman shifting of a portion of the fundamental beam in a high-pressure (400 psig) hydrogen cell. Thus the two wavelengths are transmitted simultaneously in time and, by careful alignment, in space. The radiation backscattered by the atmosphere is collected with a $90-\mathrm{cm}$-diameter telescope and the two wavelengths are separated by a series of dichroic beam splitters and interference filters. The signal is then measured using photomultipliers and photon-counting techniques. The system operates only at night and the signal is averaged for $10^{6}$ laser pulses, which takes approximately 2 hours to derive a single stratospheric ozone profile. The ozone number density is obtained from the difference of the derivatives of the signals recorded for each wavelength, divided by the ozone differential absorption cross section, taking into account the temperature dependence of this cross section, and the wavelength dependence of the Rayleigh backscatter and extinction. The slope (derivative) of the background corrected signal is computed as a function of range. As the altitude is increased, the range resolution of the measurement has to be degraded to limit the increase in the statistical error related to the rapid decrease in the signal level (see Table 3). In this particular lidar implementation the largest source of error has been found to be associated with the determination of the background signal.

\section{Millitech/LaRC Microwave}

The microwave instrument is intended for long-term ozone monitoring and is largely automated so that it requires a minimum of operator attention. It was developed at the Millitech Corporation. The data calibration and retrieval algorithms used with the instrument were developed at the NASA Langley Research Center. The instrument consists of a microwave receiver and a 122-channel spectrometer. It was tuned to observe the ozone line at $110.836 \mathrm{GHz}(\lambda=2.6$ $\mathrm{mm}$ ) for all data reported in this paper. The receiver converts signals at its input to lower "intermediate" frequencies that can be processed by conventional electronic techniques in the filter spectrometer. The spectrometer's filters are followed by detectors; the detector outputs are digitized, integrated, and stored in the system computer. The instrument is calibrated using the thermal radiation from blackbody standards. The instrument, observing technique, and calibration method are described by Parrish et al. [1992]. The ozone altitude distribution is retrieved from the details of the pressure-broadened line shape. The retrieval method is described by Parrish et al. [1992] and a detailed characterization of the results is presented by Connor et al. [this issue]; it is based on the work of Rodgers [1976]. The data reported in STOIC were 5- to 8-hour integrations, at night.

\section{ECC Ozonesondes}

The ECC ozonesonde, a compact, lightweight, balloonborne instrument, employs a wet-chemical method involving the reaction of ozone with potassium-iodide (KI) to measure the vertical distribution of ozone. The sensor is made of two bright-platinum electrodes immersed in KI solutions of different concentrations contained in separate cathode and anode chambers linked together with an ion bridge. Driving emf for sensor operation is provided by the different solution concentrations. Ozone in air, forced into the sensor cathode by a nonreactive gas sampling pump during balloon ascent, reacts with the aqueous $\mathrm{KI}$ solution to form iodine $\left(\mathrm{I}_{2}\right)$. The sensor then reconverts the $I_{2}$ to iodide, at which time two electrons flow in the sensor's external circuit corresponding to each molecule of ozone entering the sensor. A measure of the sensor's output current translates, therefore, into the rate of ozone entry into the sensor per unit time. During balloon ascent the ECC instrument is connected to a meteorological radiosonde for ozone data transmission to a ground-receiving station. Transmitted data include air pressure, temperature, and relative humidity. See Komhyr et al. [this issue(a)] for more details.

ECC ozonesondes flown during STOIC by NOAA and WFF personnel were essentially identical, but operating 
procedures were different in some respects. These differences are traditional between the two institutions and were maintained here, rather than imposing a uniform procedure. ECC sensor cathode KI solutions in the WFF instruments were slightly more concentrated (by $0.5 \%$ ), causing a small difference in the stoichiometry of the $\mathrm{KI}-\mathrm{O}_{3}$ reactions in the NOAA and WFF sondes. Somewhat different pump efficiency corrections were used by the two groups at balloon flight altitudes above about 100 mbar. NOAA ECC sonde ozone profiles were normalized to Dobson spectrophotometer total ozone, while the WFF instruments were calibrated prior to flight with an ozone source of known concentration, with calibration traceable to NIST. Finally, the NOAA sonde data were processed automatically during flight, while the WFF data were manually extracted from radiosonde receiver recorder charts for processing.

\section{Dobson Spectrophotometer}

The Dobson spectrophotometer is a UV double monochromator capable of highly accurate measurements of the relative intensities of the double-pair wavelengths $A(305.5 /$ $325.0 \mathrm{~nm}), B(308.9 / 329.1 \mathrm{~nm}), C(311.5 / 332.4 \mathrm{~nm})$, and $D$ $(317.5 / 339.9 \mathrm{~nm})$ emanating from the Sun, Moon, or zenith sky. The short wavelength of each pair is highly absorbed by ozone, while absorption at the longer wavelengths is only slight. Effective band passes are $1 \mathrm{~nm}$ for the short wavelength and $3 \mathrm{~nm}$ for the long wavelength of each pair. Total ozone amounts deduced from direct Sun measurements are most accurate and can be made on any of the wavelength pairs, taking into account the solar elevation at the time of observation, relevant ozone absorption coefficients, and light scattering by air molecules and aerosols. To eliminate aerosol interference which is difficult to quantify, observations are made on double-pair wavelengths such as the fundamental $A$ and $D$ wavelengths. Aerosol effects are eliminated through a subtraction process since aerosol scattering is highly similar for the A and D wavelengths. All Dobson spectrophotometers in use throughout the world are calibrated periodically relative to world standard Dobson spectrophotometer 83 , whose long-term ozone measurement precision has been maintained at $\pm 1 \%$ since 1962 [Komhyr et al., 1989]. Ozone measurement precision for the instrument is $\pm 0.3 \%$, and ozone measurement accuracy is estimated to be $\pm 3.0 \%$.

During STOIC, ozone vertical profiles [Komhyr et al., this issue(b)] were also made with the Dobson instrument employing the Umkehr technique [Gotz et al., 1934; Mateer and Dutsch, 1964; Mateer and DeLuisi, 1992]. Umkehr observations are made in mornings or afternoons on light scattered from the clear zenith sky. The measurements are based on the principle that the effective scattering height in the atmosphere for any of the Dobson instrument pairs, e.g., C, varies during times of rising or setting Sun.

\section{Brewer Spectrophotometer}

The automated Brewer ozone spectrophotometer was developed during 1979-1981 at the Atmospheric Environment Service (AES) in Canada for the purpose of measuring column ozone operationally with the high stability necessary for accurate long-term trend analysis. It is a modified Ebert grating spectrophotometer which can be programmed to sequence automatically measurements of total ozone (using the direct Sun, zenith sky, or focused Moon measurement method), the ozone profile using the Umkehr method, and UV-B radiation. The World Meteorological Organization Brewer instrument 39 was used during STOIC to measure total ozone using the direct Sun method [Kerr and McElroy, this issue] and the ozone profile using the Umkehr method [McElroy and Kerr, this issue]. The instrument and the methods to measure total ozone are described by Kerr et al. [1983, 1985] and Evans et al. [1987], and the Umkehr method for ozone profiles by Mateer et al. [1985], McElroy et al. [1989, this issue], and McElroy and Kerr [1990].

\section{ROCOZ-A}

The improved rocket ozonesonde (ROCOZ-A) is launched aboard a Super-Loki booster to approximately $70 \mathrm{~km}$, where the payload is ejected for parachute descent. The radiometer measures the solar UV irradiance over its filter wavelengths as it descends through the atmosphere. The amount of ozone in the path between the radiometer and the Sun is then calculated from the attenuation of solar flux as the instrument falls. In addition, radar from the launch site measures the height of the payload throughout its descent which, combined with knowledge of the solar zenith angle, allows calculation of the overhead ozone column as a function of geometric altitude. Ozone mixing ratio can be calculated as the derivative of the column amount with respect to pressure. The ROCOZ-A and its performance are described more fully by Barnes et al. [1989].

\section{Results and Discussion}

Plate 1 shows the "blind" results from a "sample" day, July 24, 1989, referred to as 890724 (in YYMMDD format), the day being UT. This was the only day in the 2-week period that had results from all instruments, due to the limited SAGE II overpass opportunities (three) and the limited ROCOZ launches (six). As can be seen from the linear and semilogarithmic presentations, the results are in very good agreement. It is obvious from the profiles that the GSFC lidar falls off above $\sim 42 \mathrm{~km}$, due to rapidly decreasing signal returns coupled with difficulties in treating signalinduced noise in the background region of the lidar return, a common problem for high-powered lidars not equipped with a shutter in front of the detectors. There was no uniform, fixed maximum altitude for cutoff; rather it varied from day to day in the blind submissions. A similar dramatic increase in uncertainty occurs in the JPL lidar for the same reason, albeit at a slightly higher altitude due to the increased laser power of the JPL system. Following an examination of the data at the end of the campaign, revisions were made to some instrument data sets. These revised profiles are shown in Plate 2. For these profiles, as well as all others in this overview, the individual profiles were interpolated using a cubic spline function onto $0.5-\mathrm{km}$ spacing to permit direct comparison.

Atmospheric variability has always been an issue that has hampered measurement intercomparisons. To minimize its effect here, the campaign was carried out during the summer which is a period of reduced variability, and attempts were made to make measurements as close together in time and space as practical. One indication of the extent of atmospheric variability during this period is obtained in Plate 3, which shows the daily average profiles, obtained for each day by simply averaging the available measurements. Figure 
890724 BLIND DATA
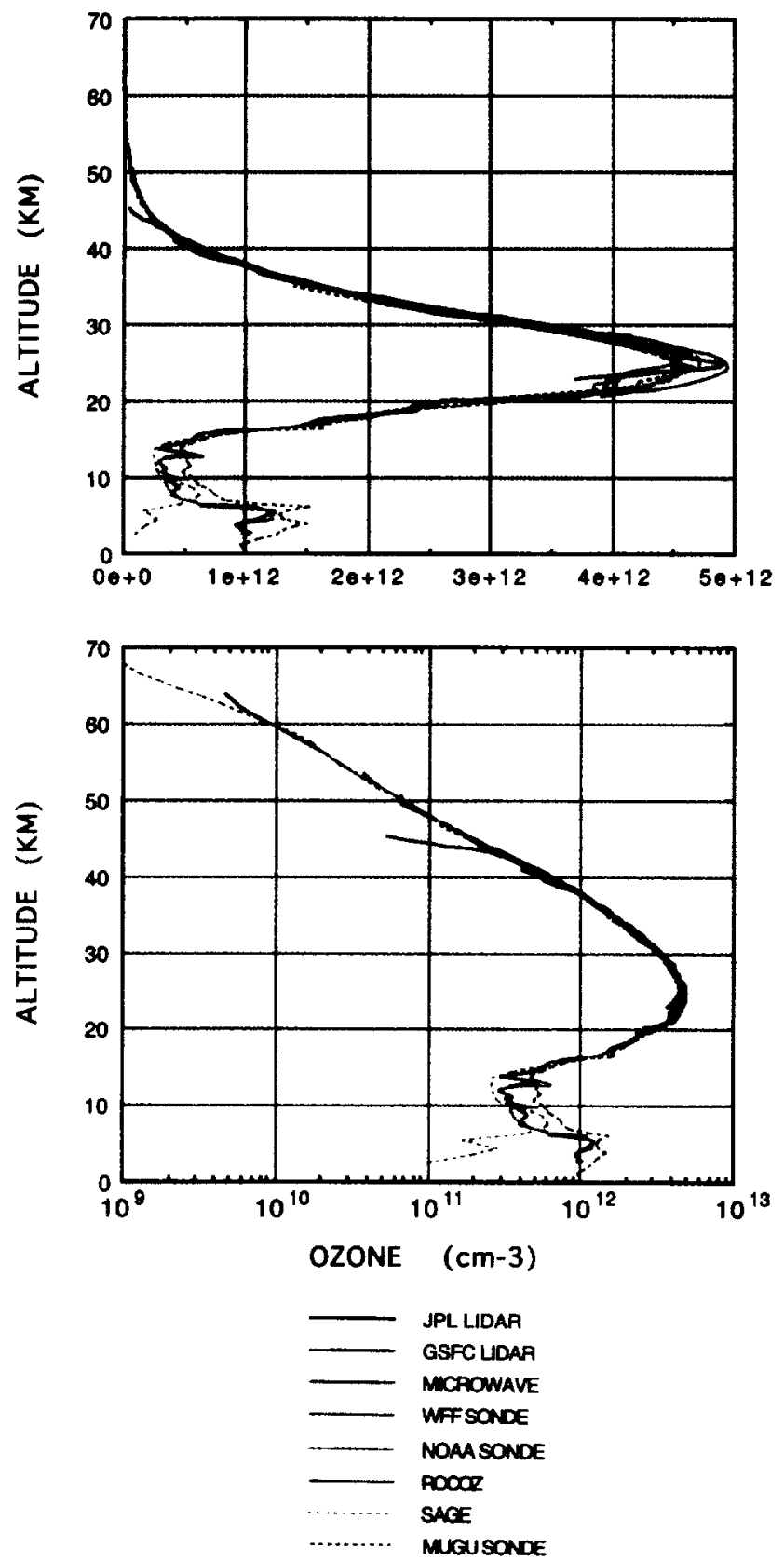

Plate 1. Ozone data for July 24, 1989. "Blind" data from all instruments. (top) Linear ozone scale; (bottom) logarithmic ozone scale.

2 shows the data as a contour plot. Since not all instruments measure ozone each day and, as will be discussed later, there are some instrument-to-instrument variations, the variability shown in Plate 3 and Figure 2 is slightly enhanced over the true atmospheric variability. Nonetheless, the conclusion from Plate 3 and Figure 2 is that atmospheric variations during the daily measurement period were small.

Given the limited day-to-day variability during this period, it was appropriate to compute an average profile for each instrument, obtained from the individual day's data, even though not all instruments made measurements on all days.
These instrument average profiles, for the blind data, are shown in Plate 4. It is clear from Plate 4 and from Plate 1 that the excellent agreement among the techniques makes it difficult to visualize the differences, when plotted in any usual manner. We therefore began comparing instruments to reference profiles and plotting the differences of the individual instruments from the reference. To try to keep the average difference near zero, it was most appropriate to compute internal STOIC references, rather than attempting to use some independent, external reference profile, which would have given rise to systematic offsets. This is not to

\section{REVISED DATA}
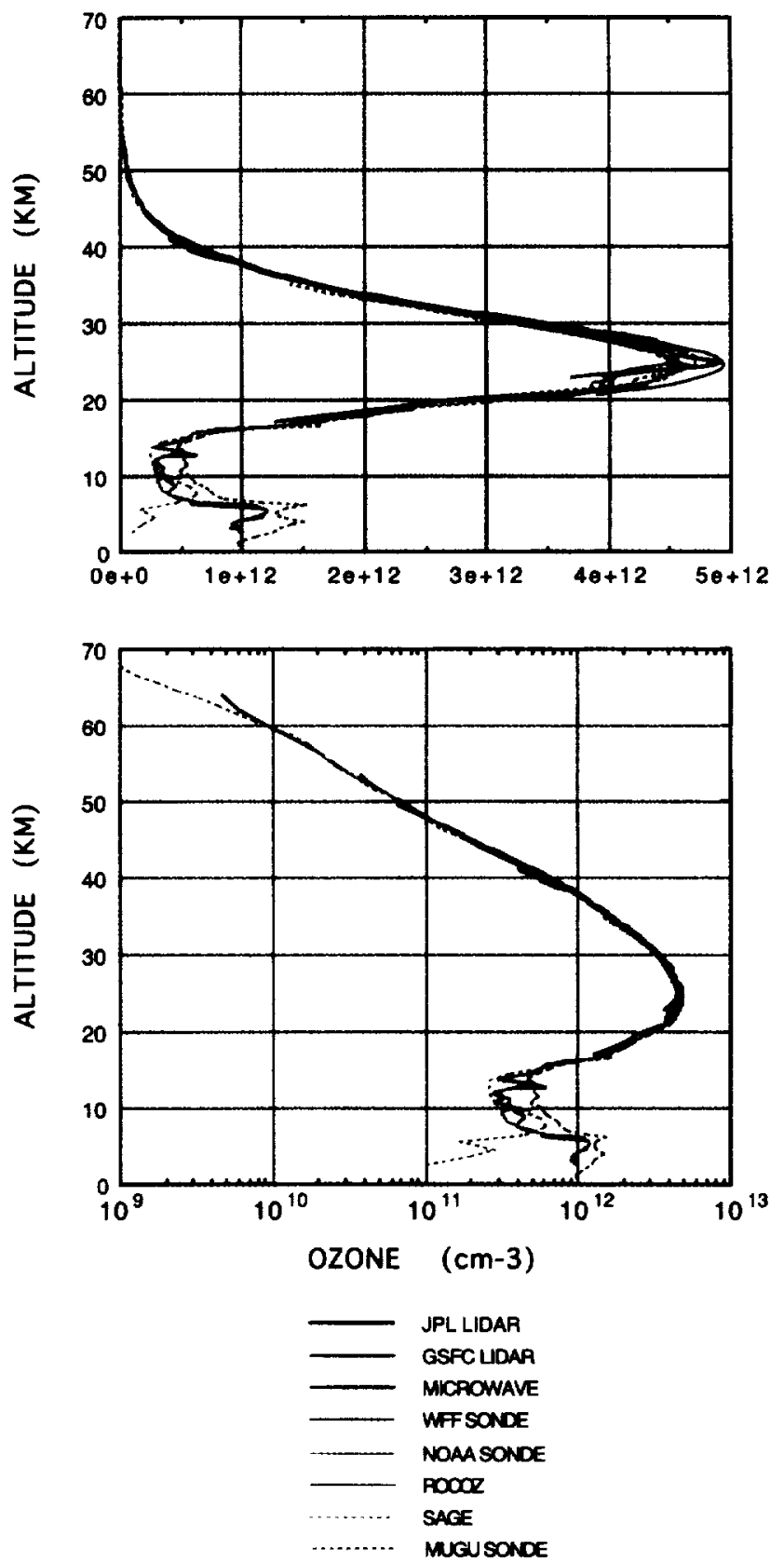

Plate 2. Ozone data for July 24, 1989. "Revised" data from all instruments. (Compare to Plate 1). (top) Linear ozone scale; (bottom) logarithmic ozone scale. 
DAILY AVERAGE PROFILES
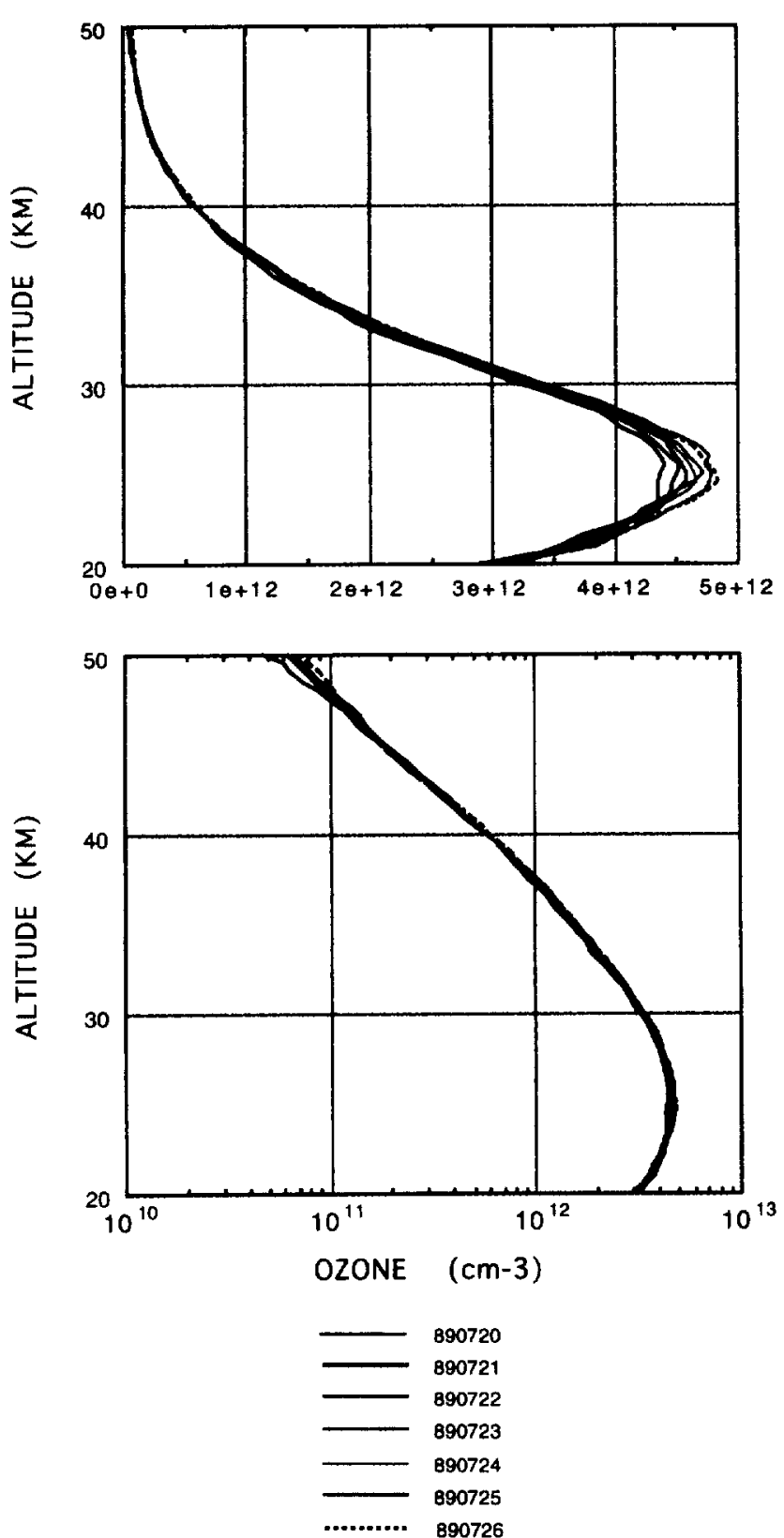

DAILY AVERAGE PROFILES
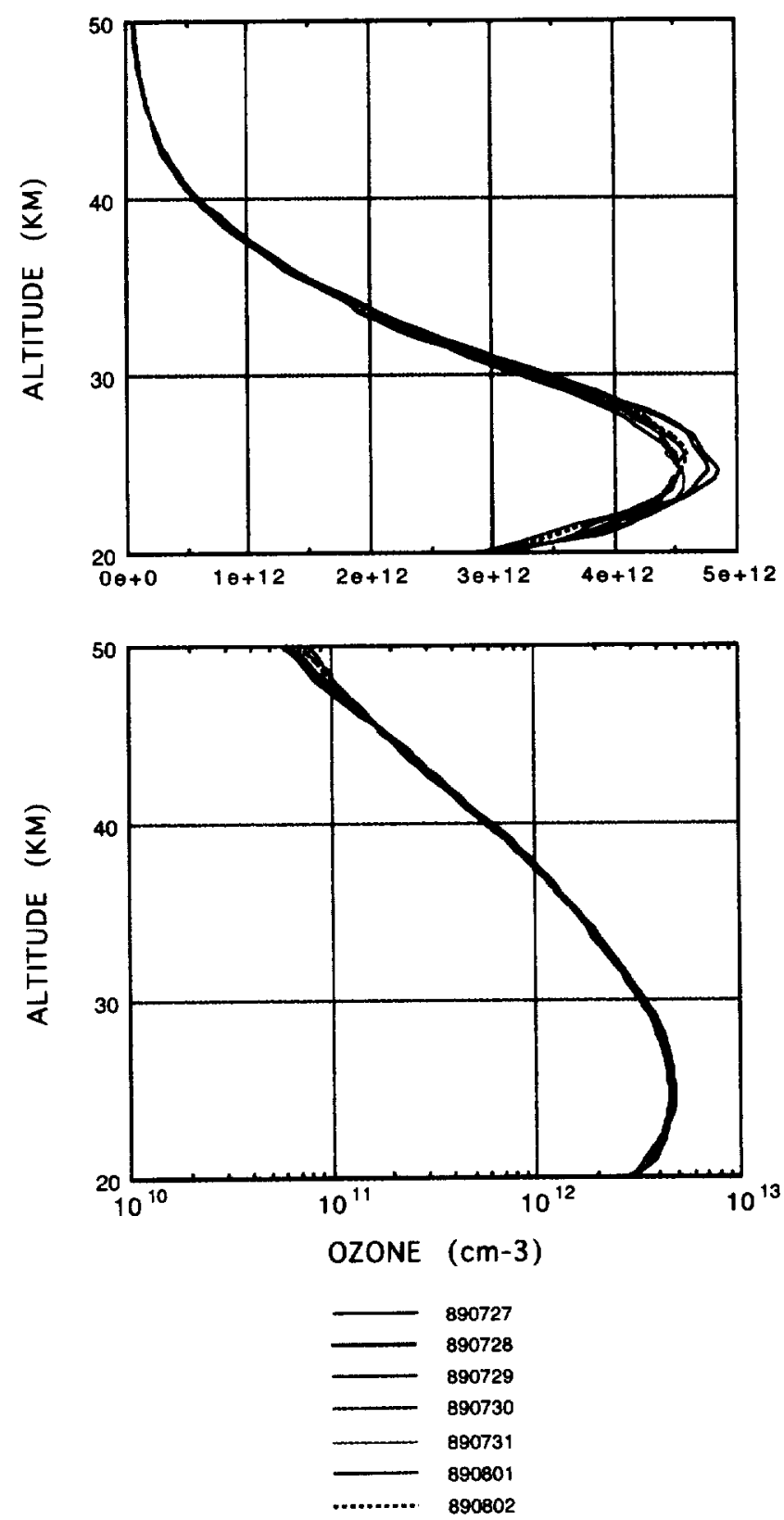

Plate 3. Daily average profiles over the campaign, showing the degree of day-to-day variability in ozone that occurred. (top) First 7 days, linear scale; first 7 days, log scale. (bottom) Second 7 days, linear scale; second 7 days, log scale.

imply that the STOIC measurements represent the "correct" atmospheric profile, although, since these are purported to be among the best ozone measuring techniques, it should be very close. Any reference profile, computed by averaging the different measurements, will have errors in it arising from contributions from the individual measurements. Thus deviations of an individual measurement from the reference cannot be construed as proof of a deficiency in that technique: even a "perfect" measurement will show differences from the reference since the reference was computed from "imperfect" data.

Several different approaches were taken to formulating reference profiles. First, the measurements for each day were averaged to obtain daily average profiles (the ones shown in Plate 3), and the individual measurements were then ratioed to that daily average, on a day-by-day basis. These differences were then plotted and examined. While this approach provides a wealth of useful data, it contains the flaw that the instruments contributing to a given day's average change from day to day, and the individual instrument biases can cause the average to "shift" from day to day. To obtain a more consistent picture of instrument biases, all the available profiles from the 2 -week period were averaged into a STOIC reference profile. This clearly does 
STOIC OZONE RESULTS

OZONE NUMBER DENSITY $\left(x 10^{12}\right.$ molecules $\left./ \mathrm{cm}^{3}\right)$

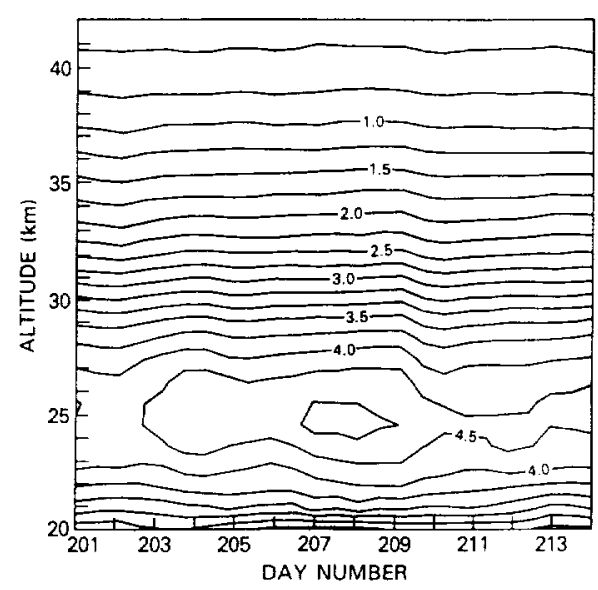

Figure 2. STOIC ozone variability shown as a contour plot over the 14-day period. Note that there was little day-to-day variability except near the peak, where it was about $10 \%$.

not given each instrument equal weight since each instrument had a different number of observations. It does, however, provide a single, consistent "normalization" profile against which all the individual profiles can be compared. The alternative technique of averaging the individual instrument averages led to a virtually identical profile.

This procedure was first carried out using the blind data. Comparisons of the individual profiles against this blind reference led to the identification of a number of instrumental problems. Some of these were as straightforward as, for example, discovering software errors causing the first point in a profile to be artificially low. Identification of these problems allowed for the generation of revised data sets which could then all be averaged into a revised reference profile, which did not include such instrument artifacts. The individual profiles could then be better compared against this better, more correct, revised reference. It is this revised reference profile that we refer to as the STOIC reference profile. The blind and revised instrument averages are compared to this STOIC reference in Plate 5, plotted as ((individual/reference)-1), so that 0.1 represents an instrument $10 \%$ higher, and -0.1 represents one $10 \%$ lower than the reference. These comparisons were carried out for the 20 - to $50-\mathrm{km}$ altitude range of interest. Since both the blind and the revised comparisons in Plate 5 use the same reference, the small effect of revisions can be seen in that figure. The revisions that occurred for the individual instruments are discussed in detail in the individual papers of this issue and are only briefly summarized here.

\section{Data Revisions}

Eight of the 12 GSFC profiles were revised above $40 \mathrm{~km}$ after an analysis of the data. In all cases the revision consisted of a truncation of the profile at a lower altitude than previously reported. The truncation point was selected where the GSFC profile began to deviate systematically (always negatively) from the daily average. Below $40 \mathrm{~km}$ the blind and revised profiles are identical. The reasons for this systematic error are discussed by McGee et al. (this issue).
Three significant features were noted in the comparison of the JPL-lidar blind profiles with the overall averages. First, at $45 \mathrm{~km}$ the comparison had an obvious inflection and the magnitude of the lidar deviation from the average started to increase rapidly. Second, there was a small but consistent difference, of the order of $5 \%$, just above $30 \mathrm{~km}$ altitude where the high- and low-intensity profiles were joined together. Third, the very first point, at $20 \mathrm{~km}$ altitude, was always low by approximately $10 \%$. These three points were carefully studied to see if there was a scientifically justifiable explanation and possible correction.

The problem identified at $\mathbf{2 0} \mathrm{km}$ was caused by an error in

\section{STOIC INSTRUMENT AVERAGES -- BLIND DATA}
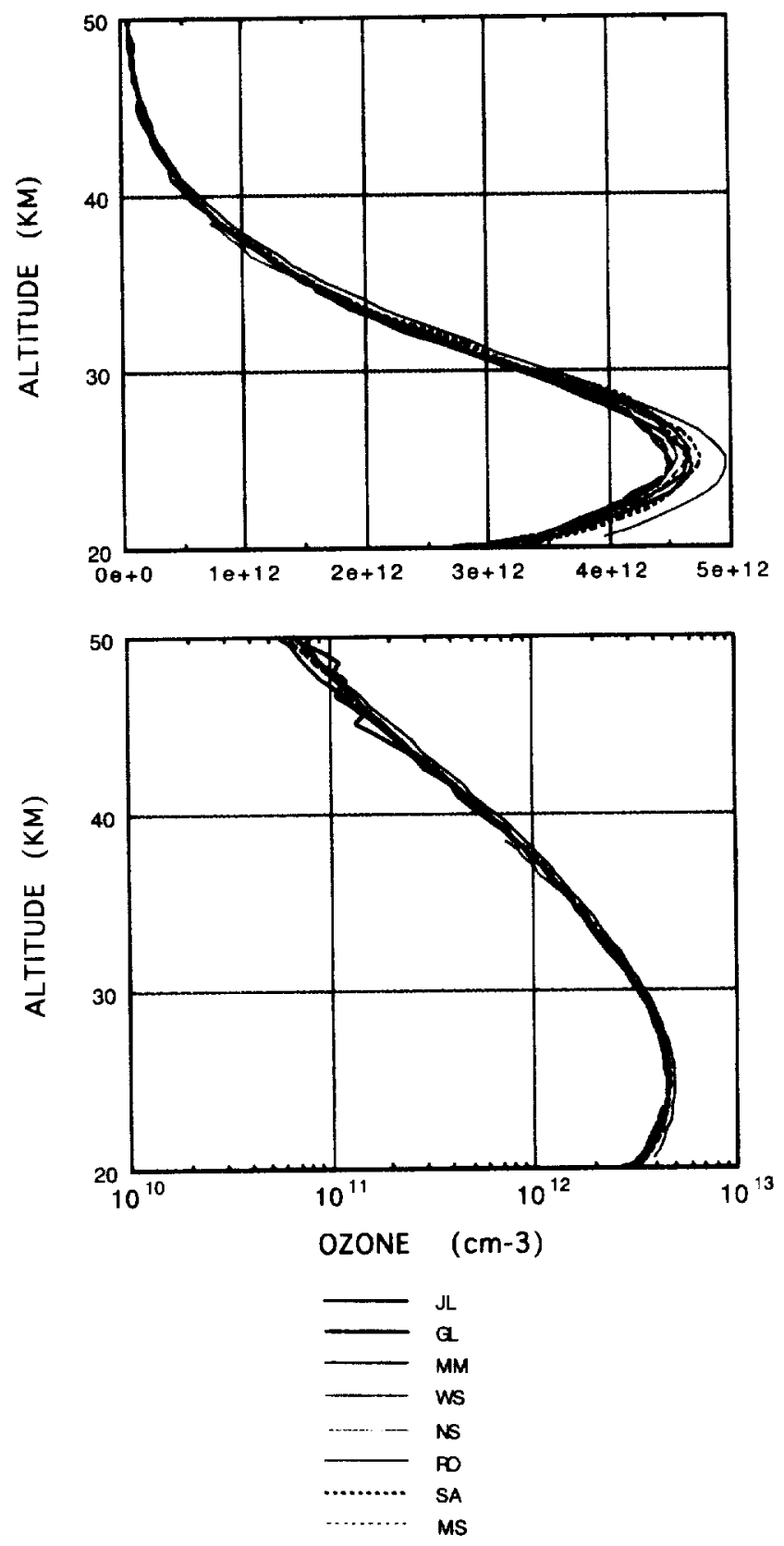

Plate 4. Blind instrument averages over the period. (top) Linear scale, (bottom) log scale. 
COMPARISON OF INSTRUMENT AVERAGES TO REFERENCE PROFILE (BLIND DATA)

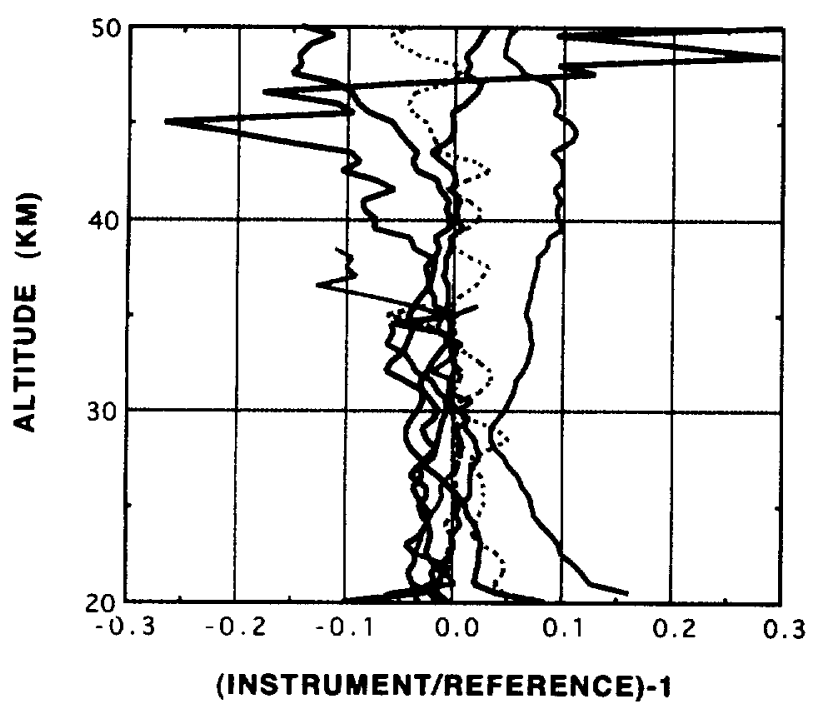

COMPARISON OF INSTRUMENT AVERAGES TO REFERENCE PROFILE (REVISED DATA)

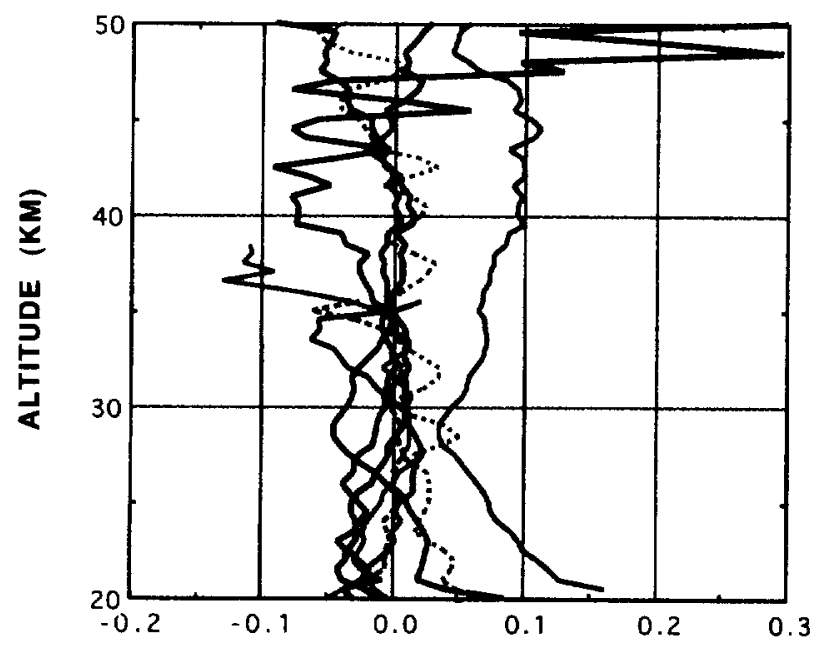

(INSTRUMENT/REFERENCE)-1

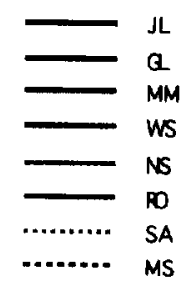

Plate 5. (top) Comparison of blind instrument averages to the STOIC reference profile (see text). Plotted as ((instrument/reference)-1); that is, 0.1 is an instrument that was $10 \%$ above the reference. (bottom) Similar to (top panel) but for the revised data. The STOIC reference is the same for both plots, so that changes are due solely to revisions to the instrument data, not the reference. the data analysis algorithm that incorrectly considered the raw data at lower altitudes in calculating the derivative of the signal at $20 \mathrm{~km}$. This was readily corrected by starting the analysis calculations at a lower altitude.

The original rationale for using high- and low-intensity data to form a composite ozone profile was to avoid the need to apply a saturation correction to the raw data counts. It was apparent from the blind intercomparison that the highintensity data still showed a small degree of saturation immediately above the crossover point. The adopted solution was to apply a correction to the high-intensity data for saturation or pulse pileup caused by the finite dead-time of the photon-counting system. This is described in detail in the paper by McDermid et al. [in this issue].

At the upper end of the altitude range, the high-intensity data, and in particular the 307.9-nm channel, have been seen to be affected by a signal-induced noise [McDermid et al., $1990 \mathrm{a}$ ], caused by the very high intensity of laser radiation backscattered from the boundary layer and the lower troposphere, hitting the photocathodes of the photomultiplier detectors. The effect of this signal-induced noise is to increase and cause a curvature of the background level. Different methods of fitting the background have been studied [McDermid et al., 1990a; Iikura et al., 1987] and the best fit is given by a nonlinear least squares exponential regression. The ozone profile below $\sim 40-45 \mathrm{~km}$ is insensitive to the method used to estimate the background. However, above this altitude the profile is very sensitive to the background correction. For the nonlinear exponential fit it is also found that the profile is sensitive to the starting altitude of the regression. For the final refined results, the background fitting for the 307.9-nm high-intensity channel was started at $85 \mathrm{~km}$ for all data sets. The only improvement in the agreement of the results above $45 \mathrm{~km}$ was achieved by truncating some of the profiles. Based on consideration of the signal levels which were affected by clouds or other conditions, some of the profiles were terminated at $47 \mathrm{~km}$ instead of $50 \mathrm{~km}$.

Revisions to the microwave data were small and were made only for July 28 and 31 . In both cases the GSFC lidar temperature profiles, which were used in processing the microwave data, were themselves revised subsequent to the campaign. The microwave data were then reprocessed using the new temperatures. Changes in the microwave ozone retrievals were between $2-4 \%$. On July 31 the revisions only affected altitudes above $50 \mathrm{~km}$.

For the blind data, NOAA ECC sonde and Dobson total column data were processed on the Vigroux [1953, 1967] ozone absorption coefficient scale, a practice sanctioned by the International Ozone Commission. Because ozone measurements made with the other instruments during STOIC (except for the microwave instrument) were expressed on the newer Bass and Paur [1985] absorption coefficient scale, the NOAA values were reduced for compatibility by $3 \%$ to form the "revised" data sets. (More recently, Komhyr et al. [1993] have shown that the difference in the two scales in $2.6 \%$; however, this $0.4 \%$ change has not been made to the data used here.) Final NOAA ECC data were processed using pump efficiency corrections determined experimentally in July 1989. These were lower than those used during initial processing of the data by $5 \%, 3 \%$, and $1 \%$ at instrument ascent altitudes of about 39,36 , and $31 \mathrm{~km}$, respectively. 
STANDARD DEVIATIONS FROM AVERAGING PROFILES:

DAILY AVGS., ALL INDIVIDUAL (REVISED), ALL INDIVIDUAL (BLIND)

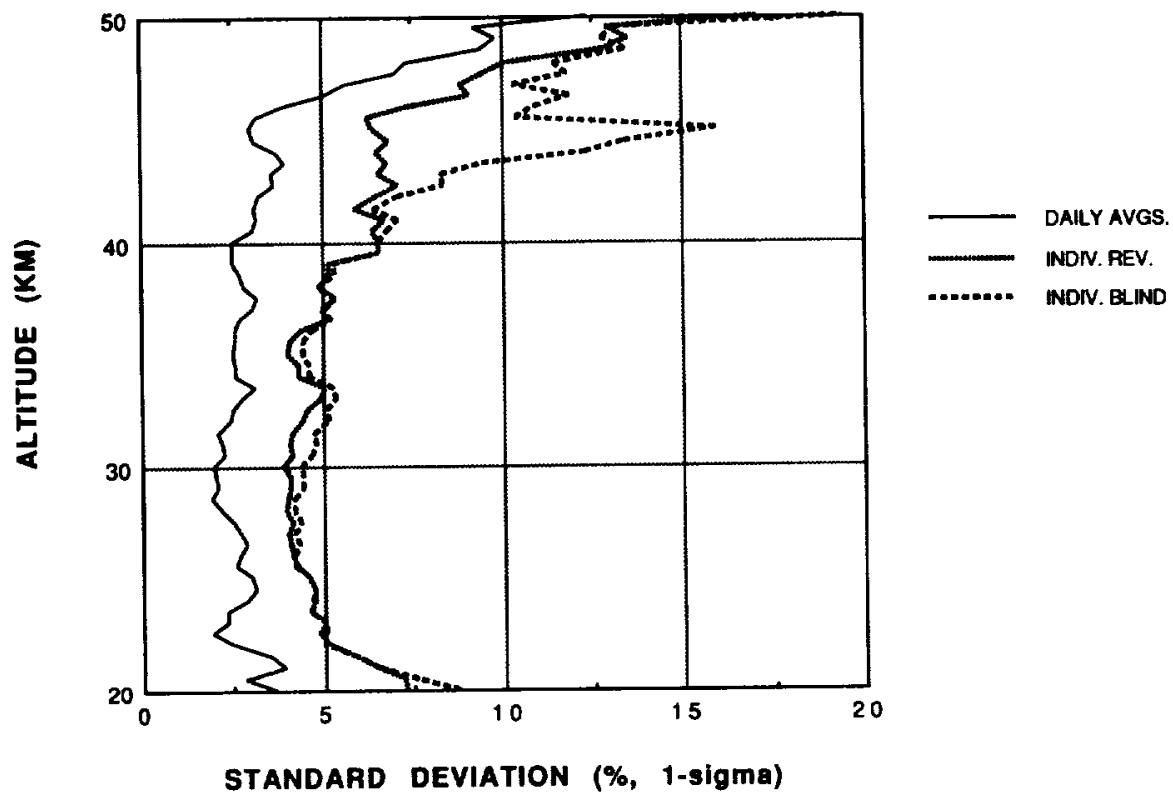

Figure 3. Standard deviations of the data versus altitude, showing atmospheric variability, and the deviations in both blind and revised instrument profiles.

There were some differences also in the blind and revised atmospheric pressures measured with the NOAA ECC sondes, primarily because of the newness of the NOAA automated sonde data acquisition system used at TMF, and inadequacy of the preliminary algorithm used for processing the radiosonde pressures. Changes made later to the algorithm allowed the pressures to be corrected.

\section{Conclusions}

The comparisons of the blind data provide an appraisal, for each technique, of the composite of the capability of that technique, the expertise of the particular group using it, and the maturity or evolution in the data analysis. From the standpoint of identifying the performance capability of the techniques for use in obtaining stratospheric ozone profiles, it is more valuable to concentrate on examining the comparisons of the revised data, which more clearly isolate the technique's inherent capability from the operator's capability. (The blind comparisons, however, provide an important indication of the potential limitations of using the data from an instrument obtained in an isolated setting.) The comparison of instrument averages to the reference in Plate 5 leads to a number of obvious conclusions regarding the performance of the various instruments. These are discussed in greater detail in the accompanying individual papers and only briefly here.

The most striking feature of Plate 5 is the excellent agreement among the techniques, measuring ozone within about $\pm 5 \%$ over the 20 - to $40-\mathrm{km}$ region. In Plate 6 the individual day's data are plotted. The revised data are shown, since they better represent the performance of the instruments. In these plots, the individual profiles have been compared to the 14-day STOIC reference profile, not to the day's average. Thus the spread of results among the instru- ments should be noted, not the deviation from 0 since small day-to-day changes in ozone will lead to the mean for each day differing from 0 . Also, on several days, a significant vertical structure is apparent, showing up in the lidars and sondes in the 20 - to $25-\mathrm{km}$ region, clearly real structure on those days but washed out in the average. The comparisons are done using the reference profile since it is being used here chiefly as a "scaling" factor to allow the profiles to be plotted on an expanded scale. As discussed earlier, daily averages are affected by the different combinations of instruments contributing on different days. These individual daily comparisons generally show a spread of about $10 \%$ (or $\pm 5 \%$ about a central value) over the 20 - to $40-\mathrm{km}$ range (with some exceptions), consistent with the instrument averages comparison in Plate 5. Detailed assessments of an individual instrument's performance on a day-by-day basis are contained in the individual instrument papers in this issue.

In Figure 3 the standard deviations are shown, which also illustrates the little change between blind and revised data, the agreement among the techniques, and the decrease in performance above $\mathbf{- 4 0} \mathrm{km}$, arising from three sources: decreasing ozone abundance, decrease in available data, and rapid falloff in signal among the remaining lidar data sets. It seems reasonable to conclude, from Plates 5 and 6 and Figure 3, that ozone measurements can be made to within about $\pm 5 \%$ over the 20 - to $40-\mathrm{km}$ region. Below about $35 \mathrm{~km}$ there are a significant number of data contributors: two lidars, microwave, three sondes. By $35 \mathrm{~km}$ the sonde performance falls off, and above $40 \mathrm{~km}$ the lidars begin to deteriorate, GSFC at a lower altitude than JPL. Because of the limited number of ROCOZ and SAGE II profiles, there is a limited basis for evaluating the lidar and microwave performance above $40 \mathrm{~km}$. Very brief summary statements of the individual instrument performance are made here; the 

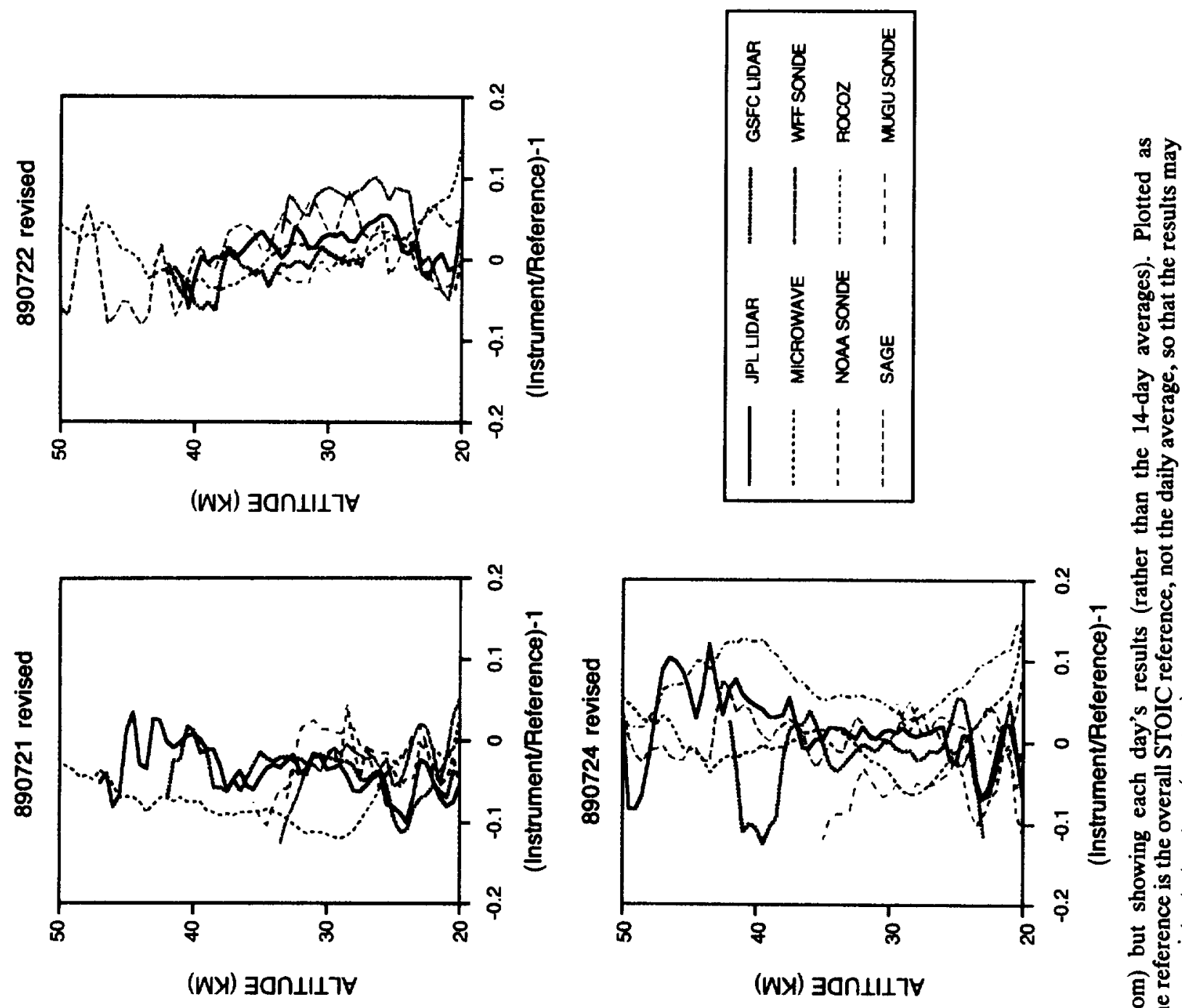

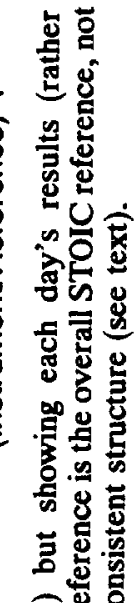

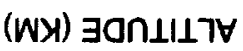
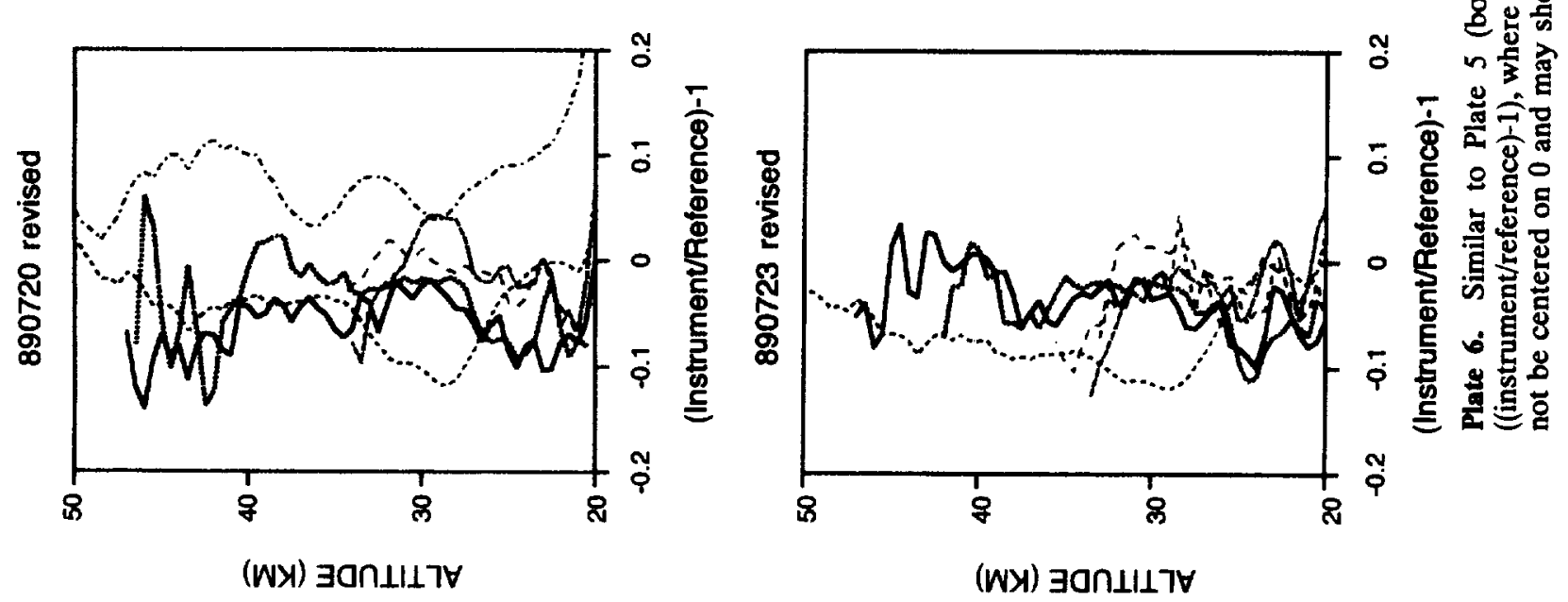


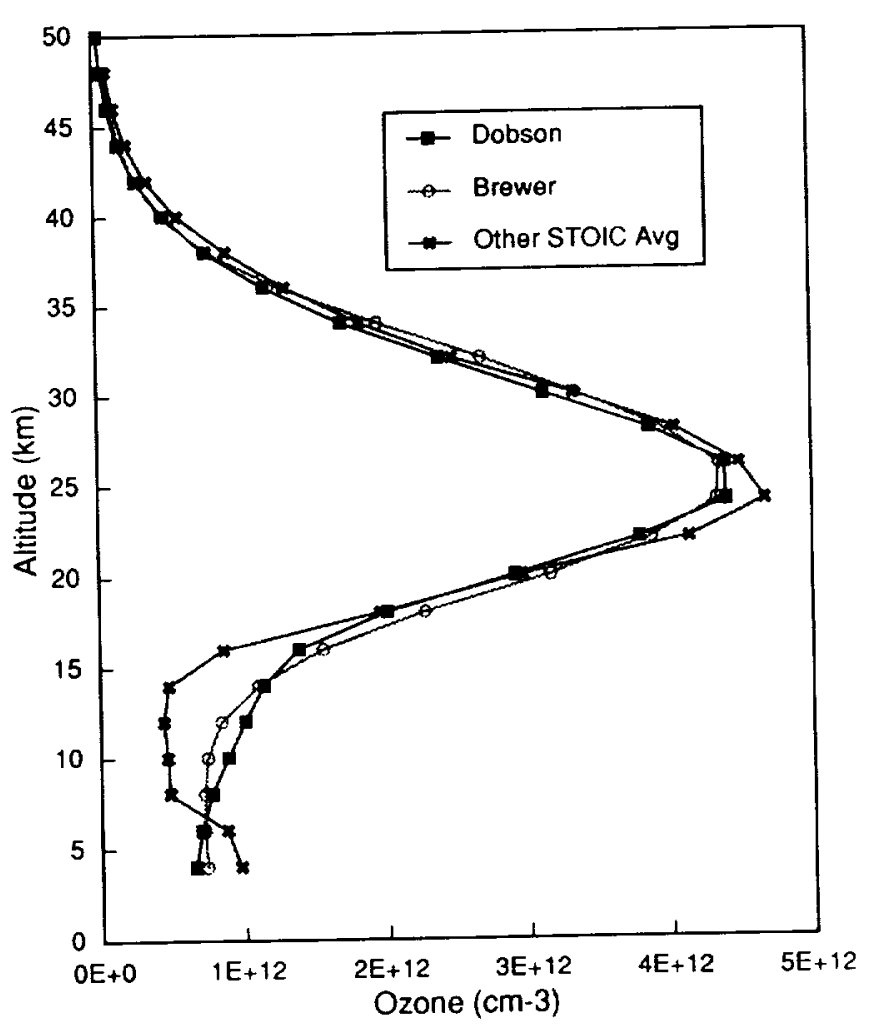

Figure 4. Comparison of the Brewer and Dobson Umkehr profiles to the mean of the other STOIC data.

generally excellent. The daily comparisons of the lidars and ECC sondes show the ability to discern significant vertical structure, especially in the lower stratosphere.

Figure 4 shows the comparison of the Brewer and Dobson Umkehr retrieved profiles to the STOIC reference. Agreement is within $15 \%$ over the 20 - to $45 \mathrm{~km}$ region and $5 \%$ between 30 and $40 \mathrm{~km}$, as discussed in greater detail by McElroy and Kerr [this issue]. The performance of the

\section{LOCAL NOON TOTAL OZONE}

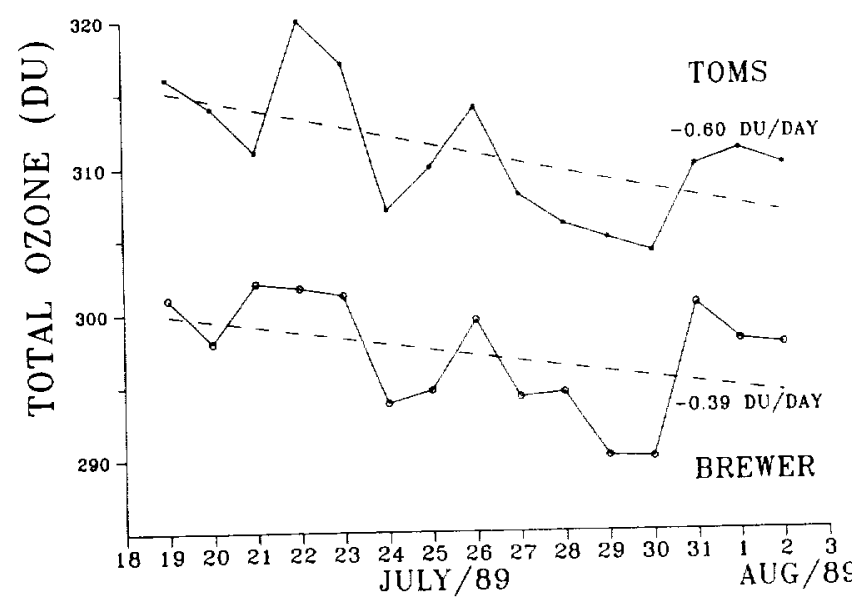

Figure 5. Comparison of total ozone column measured by the Brewer and the total ozone mapping spectrometer (TOMS).
Dobson Umkehr relative to ECC sondes is described by Komhyr et al. [this issue].

Ground-based direct Sun measurements of total ozone were made by the Brewer spectrophotometer at frequent intervals throughout each day and by the Dobson spectrophotometer several times each morning and afternoon during STOIC. The Brewer-measured daily average ozone values for all days between July 19 and August 2 are given in Figure 5. The average total ozone over the 15-day period was 297.8 Dobson units (DU) with a standard deviation of \pm 4 DU. A systematic diurnal variation of total ozone was observed throughout the period, with ozone values in the late afternoon averaging $6.6 \pm 0.7 \mathrm{DU}$ larger than in the morning. This variability can be attributed to the buildup of low-level ozone during the day [see McDermid and Walsh, this issue]. Results of 26 morning and afternoon Brewer and Dobson total ozone comparisons indicated that the Dobson instrument measured 1.2 DU $(0.4 \%)$ less ozone than did the Brewer instrument. A comparison of Brewer column ozone to that obtained by TOMS shows TOMS values about $4.6 \%$ larger, substantially different from past comparisons, possibly resulting from the high altitude of the TMF site versus the normal tropospheric correction used by TOMS. Detailed discussion of the total ozone results and comparisons with other measurements are presented by Kerr and McElroy [this issue].

\section{Overall Conclusion}

The STOIC results provide a demonstration that the instruments newly developed for the NDSC have the capability of producing highly accurate and intercomparable measurements of the ozone vertical abundance, approaching $5 \%$ accuracy over the 20 - to $40-\mathrm{km}$ range. Periodic blind comparisons such as this have value not only for establishing the credibility of various techniques but also for identifying possible improvements to instruments, algorithms, and procedures. Such campaigns should be an integral part of ongoing measurement systems, including ground-based, balloon, aircraft, and space-based sensors.

Acknowledgments. An effort such as STOIC obviously requires the cooperation of a large number of people, institutions, and agencies. Many of them are identified in the individual papers of this collection and are implicitly included here. Funding for the STOIC participants was provided by a number of sources, including NASA, NOAA, and AES/Canada. The help and cooperation of the staff of TMF and of the Navy at Point Mugu and San Nicholas Island were essential to our success. A portion of the work described in this paper was carried out by the Jet Propulsion Laboratory, California Institute of Technology, under a contract with the National Aeronautics and Space Administration.

\section{References}

Barnes, R. A., and A. L. Torres, Electrochemical concentration cell ozone soundings at two sites during the STOIC campaign, $J$. Geophys. Res., this issue.

Barnes, R. A.. M. A. Chamberlain, C. L. Parsons, and A. C. Holland, An improved rocket ozonesonde (ROCOZ-A), 3, Northern midlatitude ozone measurements from 1983 to $1985, J$. Geophys. Res., 94, 2239-2254, 1989.

Barnes, R. A C. L. Parsons, and A. P. Grothouse, ROCOZ-A ozone measurements during the stratospheric Ozone Intercomparison Campaign (STOIC), J. Geophys, Res., this issue

Bass. A. M., and R. J. Paur, The ultraviolet cross-sections of ozone, 
1, The Measurements, in Proceedings of the Quadrennial Ozone Symposium on Atmospheric Ozone, pp. 606-610, edited by C. S. Zerefos and A. Ghazi, D. Reidel, Norwell, Mass., 1985.

Connor, B. J., A. Parrish, J.-J. Tsou, and M. P. McCormick, Error analysis for the ground-based microwave ozone measurements during STOIC, $J$. Geophys. Res., this issue.

Evans, W. F. J., H. Fast, A. J. Forester, G. S. Henderson, J. B. Kerr, R. K. R. Vupputuri, and D. I. Wardle, Stratospheric ozone science in Canada: An agenda for research and monitoring, Intern. Rep. ARD-87-3, Environ. Can., Downsview, Ontario, 1987.

Ferrare, R. A., et al., Lidar measurements of stratospheric temperature during STOIC, J. Geophys. Res., this issue.

Gotz, F. W. P., A. R. Meetham, and G. B. B. Dobson, The vertical distribution of ozone in the atmosphere, Proc. R. Soc. London A, $145,416,1934$.

Hilsenrath, E., et al., Results from the Balloon Ozone Intercomparison Campaign (BOIC), J. Geophys. Res., 91, 13,137-13,152,

likura, Y., N. Sugimoto, Y. Sasano, and H. Shimizu, Improvement on lidar data processing for stratospheric aerosol measurements, Appl. Opt., 26, 5299-5306, 1987.

Kerr, J. B., and C. T. McElroy, Total ozone measurements made with the Brewer ozone spectrophotometer during STOIC 1989, J. Geophys. Res., this issue.

Kerr, J. B., C. T. McElroy and W. F. J. Evans, The automated Brewer spectrophotometer for measurement of $\mathrm{SO}_{2}, \mathrm{O}_{3}$, and aerosols, paper presented at the WMO/AMS/CMOS Symposium on Meteorological Observations and Instrumentation, pp. 470 472, World Meteorol. Organ., Toronto, Ontario, Canada, 1983.

Kerr, J. B., C. T. McElroy, D. I. Wardle, R. A. Olafson, and W. F. J. Evans, The automated Brewer spectrophotometer, in Proceedings of the Quadrennial Ozone Symposium on Atmospheric Ozone, edited by C. S. Zerefos and A. Ghazi, pp. 396-401, D. Reidel, Norwell, Mass., 1985.

Komhyr, W. D., R. D. Grass, and R. K. Leonard, Dobson spectrometer 83: A standard for total ozone measurements, J. Geophys. Res., 94, 9847-9861, 1989

Komhyr, W. D., C. L. Mateer, and R. D. Hudson, Effective Bass-Paur 1985 ozone absorption coefficients for use with Dobson ozone spectrophotometers, J. Geophys. Res., 98, 20,451-20,466, 1993.

Komhyr, W. D., J. A. Lathrop, D. P. Opperman, R. A. Barnes, and G. B. Brothers, Electrochemical concentration cell ozonesonde performance evaluation during STOIC 1989, J. Geophys. Res., this issue(a).

Komhyr, W. D., B. J. Connor, I. S. McDermid, T. J. McGee, A. D. Parrish, and J. J. Margitan, Comparison of STOIC 1989 groundbased lidar, microwave spectrometer, and Dobson spectrophotometer Umkehr ozone profiles with ozone profiles from balloonborne electrochemical concentration cell ozonesondes, $J$. Geophys. Res., this issue(b).

Mateer, C. L., and J. J. DeLuisi, A new Umkehr inversion algorithm, J. Atmos. Terr. Phys., 54, 537-556, 1992.

Mateer, C. L., and H. U. Dutsch, Uniform evaluation of Umkehr observations from the World Ozone Network, I, in Proposed Standard Evaluation Technique, $105 \mathrm{pp}$., National Center for Atmospheric Research, Boulder, Colo., 1964.

Mateer, C. L., J. B. Kerr, and W. F. J. Evans, Ozone profiles derived from Umkehr observations obtained with the Brewer ozone spectrophotometer, in Proceedings of the Quadrennial Ozone Symposium on Atmospheric Ozone, edited by C. S. Zerefos and A. Ghazi, pp. 407-411, D. Reidel, Norwell, Mass. 1985.

McDermid, I. S., and S. M. Godin, Stratospheric ozone measurements using a ground-based, high-power lidar, laser applications in meteorology and earth and atmospheric remote sensing, Proc. SPIE Int. Soc. Opt. Eng., 1062, 225-232, 1989.

McDermid, I. S., and T. D. Walsh, Surface ozone levels at Table Mountain during STOIC 1989, J. Geophys. Res., this issue.

McDermid, I. S., S. M. Godin, and L. O. Lindqvist, Ground-based laser DIAL system for long-term measurements of stratospheric ozone, Appl. Opt., 29, 3603-3612, 1990a.

McDermid, I. S., S. M. Godin, and T. D. Walsh, Lidar measurements of stratospheric ozone and intercomparisons and validation, Appl. Opt., 29, 4914-4923, 1990b.
McDermid, I. S., S. M. Godin, and T. D. Walsh, Results from the JPL stratospheric ozone lidar during STOIC 1989, J. Geophys. Res., this issue.

McElroy, C. T., and J. B. Kerr, Table Mountain ozone intercomparison: Brewer ozone spectrophotometer Umkehr observations, paper presented at the Topical Meeting on Optical Remote Sensing of the Atmosphere, Opt. Soc. of Am., pp. 445-448, Incline Village, Nev., 1990.

McElroy, C. T., and J. B. Kerr, Table Mountain ozone intercomparison: Brewer ozone spectrophotometer Umkehr observations, J. Geophys. Res., this issue.

McElroy, C. T., C. L. Mateer, J. B. Kerr, and D. I. Wardle Umkehr observations made with the Brewer ozone spectrophotometer, in Proceedings of the Quadrennial Ozone Symposium on Ozone in the Almosphere, edited by C. S. Zerefos and A. Ghazi, pp. 725-727, D. Reidel, Norwell, Mass., 1989.

McGee, T. J., D. Whiteman, R. Ferrare, J. J. Butler, and J. Burris, STROZ LITE: Stratospheric Ozone Lidar Trailer Experiment, Opt. Eng., 30, 31-39, 1991.

McGee, T. J., R. Ferrare, D. Whiteman, J. Butler, J. Burris, and M. Owens, Lidar measurements of stratospheric ozone during the STOIC campaign, J. Geophys. Res., this issue.

Parrish, A., B. J. Connor, J.-J. Tsou, I. S. McDermid, and W. P. $\mathrm{Chu}$, Ground-based microwave monitoring of stratospheric ozone, J. Geophys. Res., 97, 2541-2546, 1992.

Rodgers, C. D., Retrieval of atmospheric temperature and composition from remote measurements of thermal radiation, Rev. Geophys., 14, 609-624, 1976.

Vigroux, E., Contribution a l'élude experimentale de l'absorption de l'ozone, Ann. Phys., 8, 709-762, 1953.

Vigroux, E., Determination des coefficients moyens d'absorption de l'ozone en vue des observations concernant l'ozone atmospherique a l'aide du spectrometre Dobson, Ann. Phys., 22, 209-215. 1967.

World Meteorological Organization (WMO) Atmospheric ozone 1985, Assessment of our understanding of the processes controlling its present distribution and change, Global Ozone Research and Monitoring Project, WMO Rep. 16, Geneva, 1985.

WMO, Report of the International Ozone Trends Panel 1988, WMO Rep. 18, Geneva, 1988.

WMO, Scientific assessment of ozone depletion: 1991, WMO Rep. 25, Geneva, 1991.

R. A. Barnes and G. B. Brothers, ManTech, Wallops Island, VA 23337.

J. Burris and T. J. McGee, Laboratory for Atmospheres, NASA GSFC, Greenbelt, MD 2077 !

J. Butler and R. A. Ferrare, Hughes STX Corporation, Lanham, MD 20706.

B. J. Connor and M. P. McCormick, Atmospheric Sciences Division, NASA LaRC, Hampton, VA 23681-0001.

J. B. Kerr and C. T. McElroy, Atmospheric Environment Service, Downsview, Ontario, Canada M3H 5T4.

W. D. Komhyr, CIRES, University of Colorado, Boulder, CO 80302.

J. J. Margitan (corresponding author), I. S. McDermid, and T. D. Walsh, Jet Propulsion Laboratory, 4800 Oak Grove Drive, California Institute of Technology, Pasadena, CA 91109.

A. J. Miller, NOAA Climate Analysis Center, Washington, D. C. 20233.

M. Owens, Department of Physics, University of Maryland, College Park, MD 20742.

A. D. Parrish, Department of Physics and Astronomy, University of Massachusetts, Amherst, MA 01003.

C. L. Parsons and A. L. Torres, Wallops Flight Facility, NASA GSFC, Wallops Island, VA 23337.

J. J. Tsou, Lockheed Engineering and Sciences Co., Hampton, VA 23666.

D. Whiteman, Laboratory for Terrestrial Physics, NASA GSFC, Greenbelt, MD 20771.

(Received September 6, 1994; revised February 8, 1995 : accepted February 12, 1995.) 
